\title{
Drying characteristics of wastewater sludge according to outside air inflow conditions
}

\author{
Oh, S. H. ${ }^{a^{*}}$; Park, K. H. ${ }^{a}$; Yu, B. H. ${ }^{\text {a }}$ Kim, S. I. ${ }^{a}$ \\ ${ }^{\text {a }}$ Energy Saving Technologies Laboratory. Korea Institute of Energy Research, Daejeon, Korea \\ *E-mail of the corresponding author: Sanghyun.Oh@kier.re.kr
}

\begin{abstract}
The purpose of this study is to analyze the changes of drying efficiency according to the inflow conditions of outside air into the drying equipment during the drying process in order to reduce the energy used in the drying process of sludge. We conducted the experiment using a vertical thin film dryer. Materials used for the experiment are sewage sludge. As a result of the study, higher drying efficiency was obtained in the case of outside air inflow than in the case of no outside air inflow. In addition, optimum condition of outside air inflow was derived.
\end{abstract}

Keywords: Drying; Sludge; Drying efficiency; Air inflow condition 


\section{Introduction}

The disposal of waste such as sludge on land is a social problem in response to the prohibition of marine discharges of waste. Most of the wastes such as sludge have a very high water content and it is necessary to dry them in order to treat them on the land. Various studies have been conducted on drying for wastewater sludge treatment.

It is very important to analyze the characteristics of sewage sludge for the treatment of sewage sludge because the characteristics of sewage sludge vary according to the area and temperature. Wang et al.[1] has studied the properties and toxicity of sewage sludge in more than six regions of China. Krzeminski et al.[2] studied the relationship between the properties of the sludge and the seasonal temperature. This study suggests that the sludge varies according to the season.

In recent years, research on sewage sludge has been focused on the treatment of sewage sludge. Especially, the sewage sludge has a high water content, and therefore, a drying process is essential for the treatment. Drying process for sewage sludge treatment has been using hot air or steam. Recently, various pretreatment processes and new heat sources have been studied to improve energy efficiency. Na et al.[3] studied the improvement of dewatering performance by applying ultrasonic treatment to sludge. In this study, it was mentioned that ultrasonic pretreatment had a positive effect on sludge dewatering and also helped to reduce volume and mass of sludge.

Recently, various methods of utilizing various heat sources have been researched to reduce the energy cost for the sewage sludge treatment process. Lye Bennamoun[4] reviewed various studies on sludge drying using solar energy. There are many reasons to utilize ocean heat energy for sludge drying, but most of all to reduce the energy cost of the drying process.

This study was also conducted to reduce the energy input to the sludge drying process. In particular, the efficiency of the drying process is the most energy involves higher costs is necessary in order to take advantage of the waste.This study analyzed the characteristics of the energy efficiency change of the system by introducing outside air into the existing sludge drying process and conducted an experimental study on a method for obtaining higher system efficiency.

\section{Materials and methods}

In this study, we used a vertical thin film dryer. The vertical thin film dryer is a device for drying various sludge and waste material using. Vertical thin film dryer is using noncontinuous indirect heat drying method, drying the sludge and waste products. Figure 1 shows the vertical thin film dryer used for this study. 

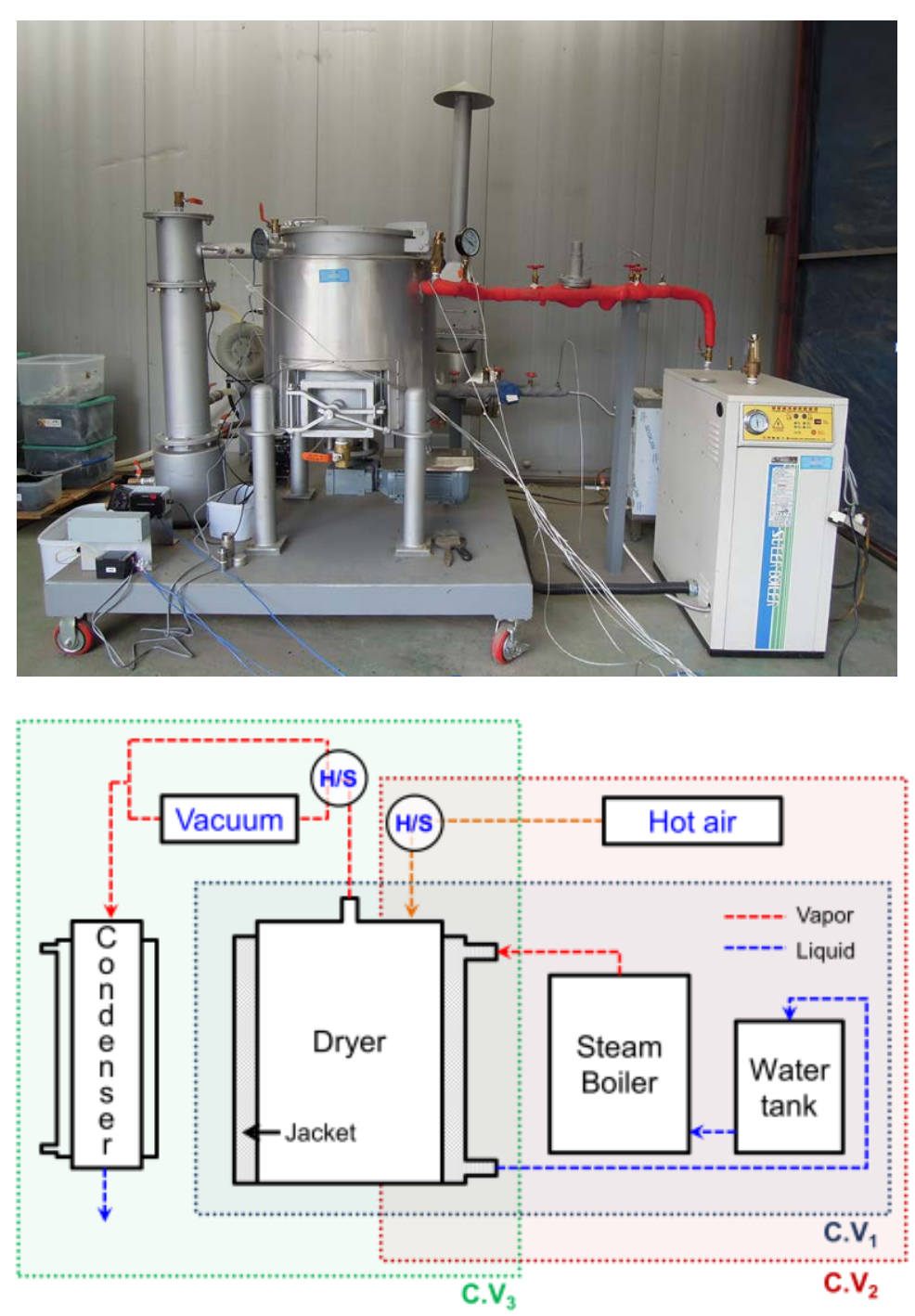

Fig. 1 The image and schematic of experimental facility.

The sludge with an initial moisture content of $80 \%$ or more can be dried to a final moisture content of 10 to $20 \%$ by using this experimental facility. The experimental facility includes a main body(dryer), a water tank, a steam boiler, an exhaust gas blower, a cooling tower, an exhaust gas condensing heat exchanger, and a platinum catalyst deodorizer. A stirrer blade is installed in the main body(dryer) so that the wastewater sludge is agitated during drying 
and the heat transfer between the material and the jacket is performed well. The material used in the experiment is sewage sludge from urban areas.

Table 1. Experimetal test cases

\begin{tabular}{cl}
\hline Cases & \multicolumn{1}{c}{ Detail } \\
\hline Inflow X & No outside air inflow \\
Inflow 1 & Inflow of air from 10 minutes after operation \\
Inflow 2 & Inflow of air from 20 minutes after operation \\
Inflow 3 & Inflow of air from 30 minutes after operation \\
Inflow 4 & Inflow of air from 40 minutes after operation \\
Inflow 5 & Inflow of air from 50 minutes after operation \\
\hline
\end{tabular}

The initial moisture content is about $80 \%$. In this study, the drying was carried out until the final moisture content was $10 \%$ or less. The pressure of the steam supplied to the system is $2 \mathrm{~kg} / \mathrm{cm} \mathrm{2}$, and the temperature inside the chamber is $155^{\circ} \mathrm{C}$ on average. The supply of steam was on / off controlled based on the pressure. The pressure and temperature were measured at intervals of 5 seconds using a data logger. In order to improve the accuracy of the experiment, only the initial water content and the final water content were measured without extracting the sample during the experiment.

As mentioned above, this study evaluated the drying performance by introducing outside air into the conventional vertical thin film drying apparatus. For the study, the experiment was carried out under the condition that no external air was introduced and the external atmosphere was introduced. The total experiment time was 60 minutes, and the detailed experimental conditions are shown in Table 1.

The purpose of this study is to improve the energy efficiency of the drying system by changing the outside air inflow operating conditions of the vertical thin film drying system. The initial moisture content and moisture content after sludge drying were measured. In order to confirm the energy input during each drying experiment, a strategic meter was installed to add the total power of all systems. The pressure inside the chamber and the relative humidity were measured so that the inside of the chamber can be confirmed. Based on this, the energy efficiency of the system is calculated and the system drying energy efficiency calculation formula is as follows.

$$
\text { Drying efficiency }=\frac{\text { Amount of water evaporation }}{\text { Input energy amount }} \times 100 \%
$$




\section{Result}

Table 2. shows the results of the experiments conducted through this study. The initial sample weight was $10 \mathrm{~kg}$. The initial and final moisture contents were measured as described above. The calculated drying efficiency is shown in Figure 2.

Table 2. Experimetal test cases

\begin{tabular}{cccc}
\hline Cases & $\begin{array}{c}\text { Material } \\
\mathbf{( k g / \mathbf { s } )}\end{array}$ & $\begin{array}{c}\text { Initial moisture } \\
\text { contents(\%) }\end{array}$ & $\begin{array}{c}\text { Final moisture } \\
\text { contents(\%) }\end{array}$ \\
\hline Inflow X & 10.08 & 80.39 & 8.7 \\
Inflow 1 & 10.08 & 83.64 & 7.36 \\
Inflow 2 & 10.82 & 83.64 & 6.7 \\
Inflow 3 & 10.17 & 83.92 & 5.17 \\
Inflow 4 & 9.99 & 78.43 & 3.31 \\
Inflow 5 & 10.17 & 82.83 & 11.82 \\
\hline
\end{tabular}

As shown in Figure 2., the drying efficiency in the condition with outside air inflow is higher than the drying efficiency in the the condition without outside air inflow. As drying proceeds in conventional drying systems, the humidity inside the dryer is kept close to $100 \%$. This means that the drying resistance is increased. However, by introducing outside air inflow, the humidity inside the chamber can be lowered during the drying process. This means a decrease in drying resistance and is directly related to improvement in drying efficiency.

Experiments were carried out by varying the outside air inflow conditions in order to check the influence of the outside air inflow in detail. In this study, the experiment was conducted for the case where the outside air was introduced after a certain period of time after the device was operated. Figure 2 shows that the drying efficiency increases as the initial operating time is kept longer and the outside air inflows to the latter part.

Generally, in the case of drying system, the drying rate is kept constant after the initial operation, so that the drying efficiency is maintained above a certain level irrespective of the inflow of outside air. However, as the drying progresses, the drying rate is reduced and the drying efficiency is reduced.

That is, if the outside air inflow is carried out at the latter stage of the experimental test, the drying efficiency of the system can be increased because the reduction in the internal drying resistance can be prevented in the drying system entering the reduced drying section. 


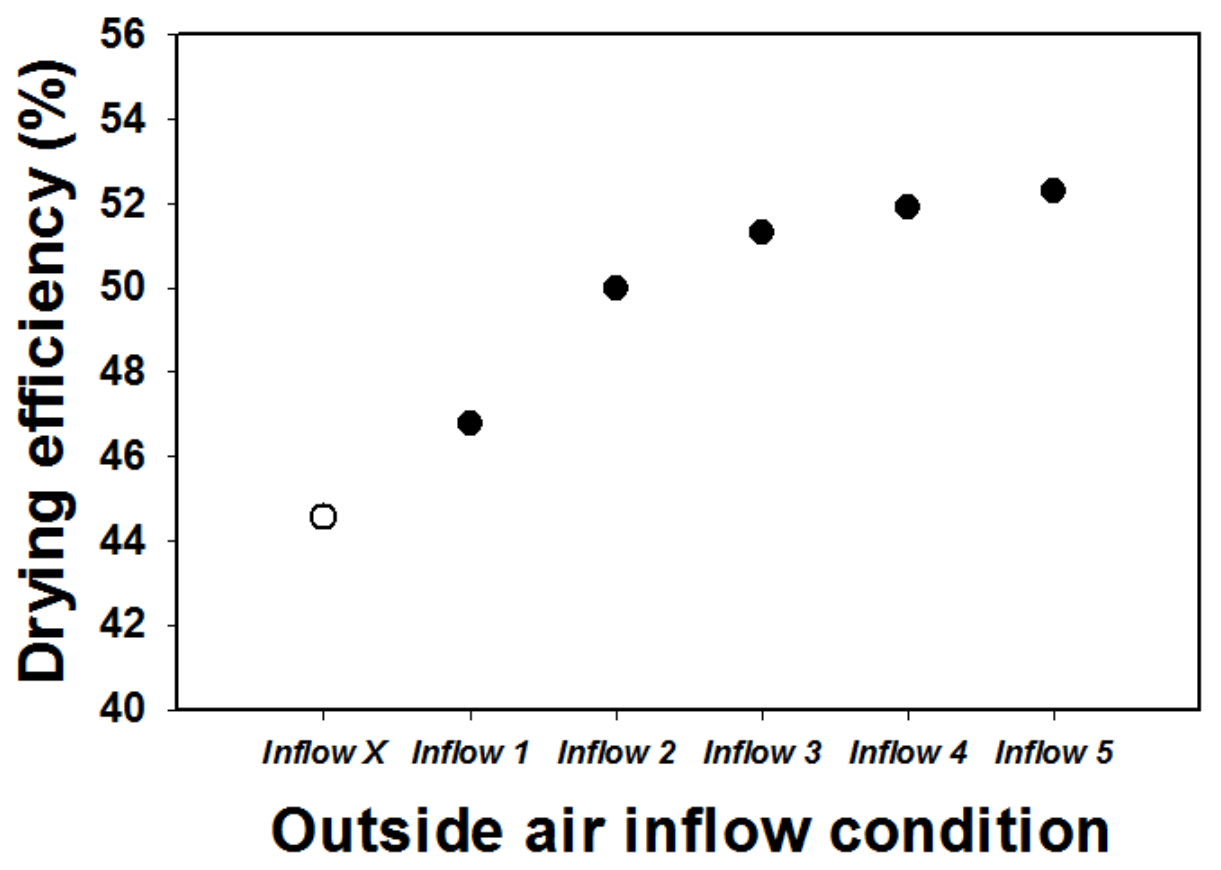

Fig. 2 Drying efficiency depending on outside air inflow conditions.

The final water content is the lowest in Inflow 4. As a result, it can be seen that there is an optimum point in the inflow condition of the outside air. Considering both final water content and drying efficiency, Inflow 4 is the optimal driving test in this study.

\section{Conclusions}

In this study, we studied about drying characteristics of wastewater sludge according to outside air inflow conditions. We conducted the experiment using a vertical thin film dryer. And experimental studies were conducted with and without outside air inflow and with various outside air inflow conditions. Materials used for the experiment are sewage sludge.

As a result of the study, higher drying efficiency was obtained in the case of outside air inflow than in the case of no outside air inflow. In addition, optimum condition of outside air inflow was derived. This is because the drying resistance inside the drying device is reduced through the inflow of outside air. Also, it was confirmed that higher drying efficiency can be obtained by progressing the inflow of air outside the rate reducing drying zone. 


\section{Acknowledgements}

This work was supported by the Korea Institute of Energy Technology Evaluation and Planning(KETEP) and the Ministry of Trade, Industry \& Energy(MOTIE) of the Republic of Korea (No. 201820101066550).

\section{References}

[1] Wang, C.; Hu, X.; Chen, M.L.; Wu, Y.H., Total concentrations and fractions of Cd, $\mathrm{Cr}, \mathrm{Pb}, \mathrm{Cu}, \mathrm{Ni}$ and $\mathrm{Zn}$ in sewage sludge from municipal and industrial wastewater treatment plants. Journal of Hazardous Materials, 2005, B119, 245-249.

[2] Krzeminski, P.; Iglesias-Obelleiro, A.; Madebo, G.; Garrido, J.M.; van der Graaf, J.H.J.M.; van Lier, J.B., Impact of temperature on raw wastewater composition and activated sludge filter ability in full-scale MBR systems for municipal sewage treatment. Journal of Membrane Science, 2012, 423-424, 348-361.

[3] Na, S.; Kim, Y.U.; Khim, J., Physiochemical properties of digested sewage sludge with ultrasonic treatment. Ultrasonics Sonochemistry, 2007, 14, 281-285.

[4] Bennanoun, L., Solar drying of wasterwater sludge: A review. Renewable and Sustainable Energy Reviews, 2012, 16, 1061-1073. 